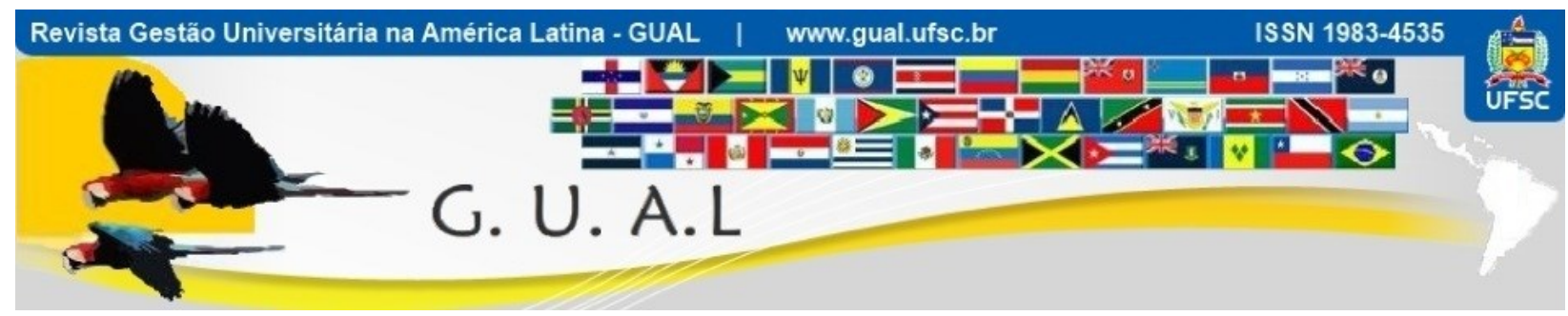

DOI: http://dx.doi.org/10.5007/1983-4535.2013v6n3p252

\title{
A INSTITUCIONALIZAÇÃO DO PLANEJAMENTO NA GESTÃO UNIVERSITÁRIA
}

THE INSTITUTIONALIZATION OF PLANNING IN UNIVERSITY MANAGEMENT

Milton Cordeiro Farias Filho, Doutor Universidade da Amazônia - UNAMA mcffarias@gmail.com

Roselene Garcia Garcia, Mestre Universidade Federal do Pará - UFPA rg@ufpa.br

Mário Miguel Amin Garcia Herreros, Doutor Universidade da Amazônia - UNAMA marioamin@gmail.com

Recebido em 30/abril/2013

Aprovado em 21/agosto/2013

Sistema de Avaliação: Double Blind Review

Esta obra está sob uma Licença Creative Commons Atribuição-Uso. 


\title{
RESUMO
}

$\mathrm{O}$ artigo tem como objetivo identificar as ações desenvolvidas no processo de planejamento institucional da Universidade Federal do Pará - UFPA e descrever as instruções normativas que desencadearam tal processo. Trata-se de um estudo com ênfase na mudança organizacional. É uma pesquisa qualitativa do tipo exploratória e descritiva e tem como fundamento o método de pesquisa-ação com uso de observação livre e fontes documentais (legislação federal e outras normas internas da Universidade) para construção de evidências. $\mathrm{O}$ conteúdo dos documentos foi analisado a partir dos conceitos do processo de institucionalização da teoria institucional para estudos de organizações. Os registros de observação serviram de complemento para descrição e interpretação dos documentos. Os resultados demonstram que a preocupação - processo de planejamento - se institucionalizou nas unidades acadêmicas, porém tal fenômeno encontrou limites e ainda está em estágio de pré-institucionalização em outras unidades, já que o sistema de acompanhamento praticamente não existiu de forma geral, o que compromete o "ciclo do planejamento". Conclui que houve avanços nas mudanças planejadas e executadas e que as características organizacionais foram modificadas, porém não ocorreu uma mudança organizacional mais abrangente.

Palavras-chave: Universidade. Planejamento. Instituições. Gestão.

\begin{abstract}
The article aims to identify the actions developed in the process of institutional planning at the Federal University of Pará - UFPA and describe the regulatory instructions that triggered this process. This is a study with emphasis on organizational change. It is a qualitative study of exploratory and descriptive and is based on the method of action research using free observation and documentary sources (federal and other internal rules of the University) to build evidence. The content of the documents was analyzed based on the concepts of the process of institutionalization of institutional theory to study organizations. Records of observation served as a complement to description and interpretation of documents. The results demonstrate that concern - planning process - was institutionalized in academic units, but such a phenomenon encountered limits and is still in the stage of pre-institutionalization in other units, since the monitoring system barely existed in general, which compromises the "planning cycle". Concludes that progress has been made on the changes planned and executed and that organizational characteristics have changed, but there was not a more comprehensive organizational change.
\end{abstract}

Keywords: University. Planning. Institutions. Management. 


\section{INTRODUÇÃO}

Mudanças ambientais influenciaram a adoção da administração estratégica pelas organizações universitárias. Esse processo tem sua origem em fatores externo e interno ao ambiente organizacional. A administração estratégia resulta do processo de adaptação organizacional (ASTLEY; VAN DE VEN, 2005) e passou a ser adotado por organizações universitárias. A estratégia é resultante da mudança e pode ocorrer de forma planejada ou voluntária (MINTZBERG, 1978). Cada organização sofre a pressão por mudança em função de seu ambiente de atuação.

A universidade, passou a adotar novos instrumentos de gestão na busca de adaptação ao seu ambiente (RODRIGUES, 2011), ao adotar o planejamento estratégico (FRANCISCO et al, 2011) para promover a modernização dos processos, a partir do desenvolvimento e da implantação de estruturas flexíveis (RIZZATTI; RIZZATTI JUNIOR, 2004).

Fortemente pressionada por ações normativas, as universidades brasileiras de gestão estatal passaram a incorporar, como fundamento de suas ações, elementos norteadores de gestão empresarial, como resultados, produtividade, qualidade e conhecimento de seus custos, qualificação de pessoal, avaliações institucionais (BRASIL, 2006; SILVA et al, 2012).

A necessidade de conciliar o planejamento integrado (RODRIGUES, 2011) na universidade com um processo sistemático para guiar decisões para a melhoria da educação e formação, investigação, desenvolvimento e integração (KAHVECI et al, 2012), levou a universidade buscar uma mudança em direção a eficiência e o planejamento estratégico foi uma das direções tratada em trabalhos recentes (RODRIGUES, 2011; SILVA et al, 2012; MIZAEL et al, 2012; FRANCISCO et al, 2011; PICCHIAI, 2012; KAHVECI et. al, 2012).

Para melhor compreensão do processo de mudança na organização universitária a pesquisa relatada neste artigo teve como base analítica a teoria institucional para estudos organizacionais, cujo foco está nos três estágios de institucionalização desenvolvidos por Tolbert e Zucker (1999). As variáveis consideradas importantes levaram ao seguinte questionamento: de que forma ocorreu o processo de institucionalização do planejamento institucional da Universidade Federal do Pará?

A pesquisa é de caráter qualitativo, cujas evidências se sustentam na análise documental (internos e externos à Universidade) e observações livres (durante o processo de planejamento) que estruturam o método de pesquisa-ação. Dessa forma a pesquisa teve como 
objetivo observar e descrever as ações do processo de institucionalização do planejamento estratégico da Universidade Federal do Pará - UFPA.

\section{PROCESSO DE MUDANÇAS NA GESTÃO UNIVERSITÁRIA}

O processo de mudanças na gestão universitária tem um incentivo externo direto, com a implantação do Plano Diretor da Reforma do Estado - PDRE (BRASIL, 1995) e uma pressão interna, com o aumento da demanda por formação superior. Do ponto de vista interno, a pressão resulta na construção de um processo de planejamento institucional que origina estudos e ações voltados para qualificação de pessoas para gerenciar as mudanças. Já a pressão externa tem como objetivo o ganho de eficiência na gestão de organizações estatais.

A administração estratégica é administração da mudança e o planejamento estratégico é uma de seus elementos. É um atributo à organização empreendedora, com o fim de prevenirem-se das incertezas com técnicas e processos administrativos que permitam a elaboração de objetivos, estratégias, métodos e ações (ANSOFF; MCDONNELL, 1992).

A administração estratégia resulta do processo de adaptação organizacional (ASTLEY; VAN DE VEN, 2005) e passou a ser adotado por organizações universitárias. A estratégia é resultante da mudança e pode ocorrer de forma planejada ou voluntária (MINTZBERG, 1978). Cada organização sofre a pressão por mudança em função de seu ambiente de atuação (interno e externo).

Um tipo específico de organização, a Universidade, passou a adotar novos instrumentos de gestão. Essa estratégia teve experiências, tais como: qualidade total, avaliação institucional (RODRIGUES, 2011) e planejamento estratégico (FRANCISCO et al, 2011), modernização dos processos, a partir do desenvolvimento e da implantação de estruturas flexíveis (RIZZATTI; RIZZATTI JUNIOR, 2004), entre outras iniciativas, mais recentemente descritas pela literatura especializada.

$\mathrm{Na}$ vertente normativa, a Lei de Diretrizes Básicas do Ensino (Lei no 9.394/96) e o Decreto $n^{0} 5.773 / 2006$ também se mostram direcionadores de mudanças nas organizações universitárias nacionais, pois trazem elementos norteadores de gestão e resultados, como produtividade, qualidade e conhecimento de seus custos, qualificação de pessoal, avaliações institucionais (BRASIL, 2006; SILVA et al, 2012).

De forma geral, Wood Jr (2000) recomenda que a organização deva se ajustar às mudanças conjunturais, políticas e econômicas, às inovações tecnológicas e aprendizagem contínua dos membros da organização. É uma necessidade de conciliar o que Rodrigues 
(2011) defende como planejamento integrado em universidade, cujo fundamento é a compreensão do ciclo de planejamento. Trata-se de um processo sistemático desenvolvido para guiar decisões para a melhoria da educação, formação, investigação, desenvolvimento e integração (KAHVECI et. al, 2012), na mesma direção ao que sustentam Silva et al (2012) sobre gestão integrada, que se dá a partir de uma estrutura eficiente de alocação dos recursos financeiros, técnicos, gerenciais e tecnológicos.

Dentre os procedimentos e metodologias para busca de uma mudança em direção a eficiência, o planejamento estratégico se mostrou uma técnica bastante usada e disseminada em organizações universitárias, como demonstrado em outros trabalhos recentes literatura nacional e (RODRIGUES, 2011; MIZAEL et al, 2012; FRANCISCO et al, 2011; PICCHIAI, 2012) e internacional (KAHVECI et. al, 2012).

Em seu estudo Rodrigues (2011) verificou que a funcionalidade do modelo de avaliação para o planejamento de forma integrada demonstrou a não compreensão, pelos gestores, do ciclo de planejamento-avaliação. Já Mizael et al (2012) encontraram como limites do Plano de Desenvolvimento Institucional-PDI, enquanto instrumento gerencial, a falta de mecanismos de divulgação e transparência, além de motivação da comunidade acadêmica para envolvimento no Plano e no processo de planejamento. Da mesma forma que Francisco et al (2011) consideram o PDI importante na estruturação do planejamento e da gestão. No entanto, mesmo considerando sua importância, Picchiai (2012) sustenta que a dificuldade de planejamento nas universidades se dá pela ausência de estrutura organizacional formalizada na área de gestão e execução de atividades.

Este panorama trouxe a necessidade de gestores universitários iniciarem processos de reestruturação de suas organizações e reordenamento de posições e atuações das universidades, na mesma forma como outras organizações que produzem bens ou prestam serviços e que precisam de respostas rápidas aos desafios da modernidade (MEYER JÚNIOR et al, 2004), demonstrando a necessidade de pensar na gestão universitária a partir da administração estratégica, não como um princípio de competição, mas como uma necessidade dos novos tempos e como forma de enfrentar demandas sociais e organizacionais.

\section{TEORIA DE BASE ANALÍTICA: A ABORDAGEM INSTITUCIONAL PARA ANÁLISE DE ORGANIZAÇÕES.}

As organizações complexas em sua definição nos estudos clássicos (ETZIONI, 1976) são por sua natureza fenômenos de difícil compreensão e cada novo estudo revela elementos 
para observação, análise e explicações particulares. O processo de mudança organizacional é um desses elementos e que não se desenvolve da mesma forma nos variados tipos de organização.

Explicações diversas e diferentes focos de análise tratam da mudança organizacional como fenômeno constante. Para Wood Jr (2000) elementos como tecnologia, comportamento social, instituições e estruturas são fatores que influenciam mudanças. A teoria institucional para estudos de organizações tem como objeto alguns desses elementos e se desenvolveu a partir de um conjunto de estudos voltados para os diferentes aspectos intervenientes no processo de mudança (MEYER; ROWAN, 2001; SCOTT; 2001; DIMAGGIO; POWELL, 2005).

Merece destaque os trabalhos de Scott (2001) e Meyer e Rowan (2001) que sustentam a não exclusividade de aspectos técnicos como determinantes de mudança organizacional, defendendo fatores institucionais, como busca por maior estabilidade e legitimidade. $\mathrm{O}$ conceito de mudança organizacional está relacionado com modificações processuais interdependentes, de natureza tecnológica, estratégica, estrutural e/ou comportamental (WOOD JR; CURADO; CAMPOS, 2000), com base em atividades intencionais, proativas e direcionadas para a obtenção das metas organizacionais (ROBBINS, 2002) de forma articulada, planejada e operacionalizada por pessoal interno ou externo à organização, que tenha o apoio e supervisão da administração superior (ARAÚJO, 1982).

Cinco perspectivas teóricas aplicadas no estudo da mudança organizacional são comumente encontradas, são elas: teoria da contingência estrutural; teoria da ecologia organizacional; teoria institucional; teoria crítica e teorias do pós-modernismo (CLEGG; HARDY, 1999). Para o desenvolvimento da pesquisa aqui relatada foi utilizada a abordagem da teoria institucional.

O processo de mudança organizacional se dá quando uma prática é considerada mais adequada para busca de melhor desempenho organizacional (DIMAGGIO; POWEEL, 2005). No entanto, uma mudança só será bem-sucedida se for institucionalizada (SCOTT, 2001), para isso a prática que está sendo implantada atravessa diferentes estágios chamados de processo de institucionalização (TOLBERT; ZUCKER, 1999).

A teoria institucional em estudos organizacionais enfatiza a maneira em que a ação é estruturada e ordenada por sistemas compartilhados de regras que, ao mesmo tempo, constrangem e capacitam os participantes do processo de mudança organizacional (DIMAGGIO; POWELL, 2005). Na concepção de Tolbert e Zucker (1999) as organizações 
tendem a utilizar práticas e procedimentos definidos racionalmente e que estão institucionalizados na sociedade, tentando aumentar sua legitimidade e suas probabilidades de sobrevivência, independente da eficácia dessas praticas e procedimentos definidos.

Esta ênfase separa a estrutura formal da organização (hierarquia, cargos, planejamentos) da eficiência técnica, já que uma organização adotará determinada estrutura não apenas porque isso contribuirá para a obtenção de melhores rendimentos técnicos, mas também porque isso lhe dará legitimidade enquanto atuante em um campo específico (DIMAGGIO; POWELL, 2005). Em função disso, os vínculos entre estas estruturas formais e a atividade técnica das organizações são frágeis (MEYER; ROWAN, 2001).

Meyer e Rowan (2001) concebem o ambiente como fator analítico primordial do comportamento organizacional. Na concepção desses autores os dois ambientes (o técnico e o institucional) aparecem mutuamente excludentes. Já Dimaggio e Powell (2005) concebem a estrutura e a técnica das organizações mais adequadas em ambientes cuja competição é livre e aberta. O ambiente institucional exerce outros tipos de pressão nas organizações. Por sua vez, Orru et al (2001) mostram que do ponto de vista analítico não há motivos para uma separação entre os dois ambientes. Enquanto Scott (2001) concebe os dois ambientes como dimensões que exercem pressões diferentes nas organizações em função do posicionamento em que se encontram.

A concepção de mudança organizacional tem também como fundamento processo de institucionalização. Uma das formas para que isso ocorra é o desenvolvimento de aspectos socialmente compartilhados. Trata-se de uma mudança processual chamado de institucionalização, que é um fenômeno sequencial com as seguintes fases: habitualização, objetivação e sedimentação (TOLBERT; ZUCKER, 1999, p. 205).

No primeiro estágio do processo de institucionalização (habitualização ou estágio préinstitucional) a organização desenvolve comportamentos padronizados para a solução de problemas específicos, em que surgem novos arranjos estruturais em resposta a problemas. Essa nova estrutura se desenvolve de forma heterogênea, o que significa que a organização como um todo tentará se moldar às novas condições ambientais, geralmente é um estágio que tem curta duração.

Já no segundo estágio (objetivação ou estágio semi-institucionalização) se desenvolvem os significados gerais socialmente compartilhadas ligados aos comportamentos. Os arranjos e os procedimentos envolvem certo grau de consenso entre os que têm o poder de 
decisão. Nessa etapa, a organização pode colher informações para avaliar os riscos de adoção da nova estrutura (TOLBERT; ZUCKER, 1999, p.208).

A objetivação se caracteriza pela difusão de uma nova estrutura, com ampliação do campo de atuação, decorrente de dois fatores: a) monitoramento interorganizacional (processo de imitação); b) a teorização, que é consequência do primeiro e quando se identificam fontes de insatisfação ou de fracasso (TOLBERT; ZUCKER, 1999, p.209). Na teorização se encontram: i) os defensores das regras de funcionamento; ii) a difusão de procedimentos formalizados de seleção e os procedimentos de avaliação de desempenho; iii) o papel desempenhado por consultores na adoção de práticas organizacionais (TOLBERT; ZUCKER, 1999, p.208).

O último estágio (sedimentação) caracteriza-se pela propagação de suas estruturas por toda organização. Mesmo na ausência de oposição, a sedimentação pode ser prejudicada pela falta de resultados demonstráveis associados à estrutura. Portanto, a total institucionalização depende da baixa resistência de grupos de oposição, da promoção e apoio dos grupos defensores e dos resultados positivos alcançados. Os fundamentos do processo de institucionalização de Tolbert e Zucker (1999) serão a base da análise do estudo do planejamento estratégico da organização universitária objeto da pesquisa.

\section{PROCEDIMENTO METODOLÓGICO E CONTEXTO DA ORGANIZAÇÃO OBJETO}

A pesquisa se fundamenta na experiência do planejamento estratégico da Universidade Federal do Pará (UFPA), no período de 2002 a 2009, por ser o período de maior influência das mudanças propostas pelo PDI 2001-2010. Esta Universidade foi criada em 1957 e estruturada em 1969. Tem 11 campi, 14 institutos, 05 núcleos, uma escola de aplicação e 2 hospitais. Em 2009 cedeu um de seus campi para formação de outra universidade (UFOPA). A Universidade tem 48.056 mil alunos, 2.634 docentes e 2.304 servidores técnicos (UFPA, 2012).

A pesquisa se classifica como uma pesquisa-ação na forma como proposta por Barbier (2007). Este tipo de estudo não requer um planejamento formal, como tradicionalmente se faz, e é realizado quando o pesquisador é objeto e sujeito, ou seja, quando está diretamente envolvido no processo que está estudando. Para seu desenvolvimento foi usada observação livre e o levantamento documental na forma como orientam Farias Filho e Arruda Filho (2013). Para isso, foi realizado um levantamento documental, sendo: 
a) documentos externos da UFPA, além de legislação diversa sobre o tema (Lei 9.394/996; Lei 10.172/2001; Lei 10.861/2004);

b) Relatórios Avalia: Programa de Auto-Avaliação da UFPA (2006 e 2008), Relatórios de Gestão da UFPA (período de 2001 a 2006), Relatório de Avaliação Institucional Externa (realizado pelos técnicos do MEC em 2009); Relatórios de Seminários de Orientações para Elaboração dos Planos de Gestão das Unidades nos Campi do interior (UFPA. 2006; UFPA, 2008);

c) Plano de Desenvolvimento Institucional (PDI) - PDI 2001-2010/UFPA; Plano de Gestão 2005-2009, Novo Estatuto e Regimento Geral da UFPA, Plano de Gestão Orçamentária (PGO) 2002-2009 (UFPA, 2003);

d) Documento Subunidades de Planejamento e Avaliação, Novos Estatutos e Regimentos das Unidades Acadêmico-Administrativas da UFPA, Sistema de Informações Gerenciais (SIG) e Outros documentos e publicações referentes à UFPA (UFPA, 2007).

Após a consulta do material os dados e informações coletados foram selecionados de acordo com a técnica de análise de conteúdo. Foi feita uma descrição analítica dos documentos, codificados e categorizados de acordo com os objetivos da pesquisa, como propõe Bardin (2010).

Para operacionalização da análise foi desenvolvida uma matriz de acordo com as orientações de Farias Filho e Arruda Filho (2013). Na matriz foram também inseridas informações coletadas nas observações livres. Para isso se considerou as três etapas principais, relacionadas aos estágios de institucionalização propostos por Tolbert e Zucker (1999) e os princípios da abordagem institucional para análise de organizações, cujos principais conceitos foram relacionados com o conteúdo dos documentos estudados.

\section{RESULTADOS DA PESQUISA}

\subsection{ESTÁGIO DE PRÉ-INSTITUCIONALIZAÇÃO (HABITUALIZAÇÃO)}

Os resultados demonstram que neste estágio os fatores que conduziram a UFPA a adotar novas práticas organizacionais foram a aprovação do PDI 2001-2010, fundamentado na administração estratégica, deixando claro o que Tolbert e Zucker (1999) concebem como comportamentos padronizados para a solução de problemas específicos, originando novos arranjos estruturais buscando se moldar às novas condições ambientais, com aprovação do novo Estatuto e do Regimento Geral da UFPA. 
O novo teor estatutário privilegiou: uma concepção multicampi; organização por área de conhecimento nas Unidades Acadêmicas (os Institutos e os Núcleos); nova estrutura de Subunidades Acadêmicas (Faculdades e as Escolas); maior autonomia aos Programas de PósGraduação, com ampliação dos vínculos obrigatórios com a graduação; representação nos conselhos deliberativos de cada nível de organização institucional (UFPA, 2006, p.130).

Execução do Programa de Capacitação do Pessoal Técnico-Administrativo, iniciando as "políticas de desenvolvimento, fixação e valorização de recursos humanos da UFPA" (UFPA, 2006, p. 64). Culminando com a criação da Pró-Reitoria de Desenvolvimento e Gestão de Pessoal (PROGEP) em 2005, também se apresenta como um fator que caracteriza o estágio de pré-institucionalização.

Modernização dos produtos e serviços de tecnologia da informação e comunicação, concepção, desenvolvimento e implantação de um Sistema de Informações Gerenciais - SIGUFPA, permitindo a integração dos dados de todos os sistemas e a criação e manutenção de uma dimensão de dados históricos, ensino, pesquisa, extensão planejamento, orçamento, pósgraduação, patrimônio etc., demonstrando transparência na gestão (UFPA, 2006, p. 69).

Tais fatores fundamentam um novo modelo de gestão, a partir da constituição de planos de trabalho por etapas, mudanças estruturais (novas estruturas), concepção de novas regras (estatuto e regimento geral), significando um estágio de desenvolvimento e preparação de metas e estratégias para aprimorar o sistema de planejamento institucional.

\subsection{ESTÁGIO SEMI-INSTITUCIONALIZAÇÃO (OBJETIVAÇÃO)}

Estágio em que foram observados os fatores que conduzem à semiinstitucionalização, evidenciando a vinculação entre os objetivos e prioridades definidas e o conjunto de decisões operacionais que foram adotadas para aprimorar o sistema de planejamento da UFPA. Nesta fase há arranjos, procedimentos e novas estruturas suficientemente disseminados e com certo grau de consenso entre os membros. O primeiro fator designado de monitoramento interorganizacional é um processo de imitação das melhores práticas encontradas (TOLBERT; ZUCKER, 1999).

A teorização é consequência do primeiro estágio, já que depois de atualizações bemsucedidas surgem práticas testadas para validação e avaliação de sua capacidade de generalização, logo, se aprovadas e aceitas pelos membros da organização, seus conceitos são organizados em uma nova teoria, caracterizando-o como um paradigma (TOLBERT; ZUCKER, 1999, p. 209). 
O aprimoramento do sistema de planejamento institucional, expresso em ações como, por exemplo, os seminários de planejamento institucional, publicação do documento e orientações para elaboração dos planos de gestão das unidades acadêmico-administrativas, foram as principais evidências encontradas para definição dos propósitos institucionais (missão, visão, princípios e diretrizes). A análise de ambiência (ameaças e oportunidades, pontos fortes e pontos fracos), proposição de desafios a serem enfrentados, elaboração de ações e definição de indicadores, estabelecimento de metas físicas quantitativas das ações também surgem como evidências do estágio de semi-isntitucionalização.

Além dessas evidências, uma proposta de uniformização de procedimentos foi elaborada pela PROPLAN e culminou com o documento de criação de Subunidades na estrutura administrativa nas Unidades Acadêmicas: a Coordenadoria de Planejamento, Gestão e Avaliação (CPGA), cujo objetivo é o de construir uma rede de planejamento interna (UFPA, 2007). Estas evidências consolidam o que Tolbert e Zucker (1999, p. 207) tratam como "desenvolvimento de certo grau de consenso social entre os decisores da organização".

\subsection{ESTÁGIO DE INSTITUCIONALIZAÇÃO TOTAL - SEDIMENTAÇÃO}

Para que ocorra a institucionalização é necessário um processo de sedimentação, no qual as ações mostram a propriedade de exterioridade, ou seja, desenvolvimento de aspectos socialmente compartilhados (TOLBERT; ZUCKER, 1999, p. 210). Neste caso a total institucionalização da estrutura depende de fatos conjuntos como "uma relativa baixa resistência de grupos de oposição, promoção e apoio cultural continuado por grupos de defensores; correlação positiva com resultados desejados". A sedimentação depende da existência de atores que não limitem a difusão das mudanças, para que se possa colocar em prática o que deveria ser adotada por necessidade organizacional.

A partir de 2002 inicia uma nova forma de gestão (gestão colegiada), por meio de fóruns, constituindo espaços institucionais de interesse comum com funcionamento e representatividade conforme dispositivos regimentais e estatutários. O princípio do colegiado de gestão reflete amadurecimento institucional. As decisões ganham representatividade e o interesse da Universidade sobrepõe-se aos interesses individuais ou de grupos.

Outro aspecto observado nos documentos pesquisados está relacionado à incorporação da nova metodologia da forma de planejar, por parte das Unidades Acadêmicas e Campi, que foi aceita pelos gestores, utilizando as diretrizes descritas no Manual de Orientações para Elaboração dos Planos de Gestão das Unidades Acadêmico-Administrativas 
da UFPA e como o ambiente organizacional está em constante variação (ABREU, 2004; UFPA, 2006). Após dois anos de implantação do Plano é possível identificar nos documentos as seguintes facilidades e dificuldades no planejamento estratégico da UFPA:

a) Facilidades: a participação gerou o envolvimento posterior e o comprometimento com a execução; a participação efetiva da Administração Superior da UFPA; abertura de novos espaços de debate e decisão com o princípio de "universidaderede", descentralização do poder (criação de várias instâncias decisórias), criando uma expectativa de mudança organizacional (ABREU, 2004; UFPA, 2006).

b) Dificuldades: a falta de investimentos em infraestrutura; não reposição de quadros funcionais; a expansão dos números de cursos; distanciamento operacional entre os Campi; restrições orçamentárias que desafiam a capacidade gerencial (ABREU, 2004; UFPA, 2006).

\subsection{SÍNTESE DOS ESTÁGIOS DE INSTITUCIONALIZAÇÃO}

A Figura 1 ilustra uma síntese do processo da prática de planejar na UFPA a partir de 2002 na forma como cada estágio do processo institucional foi desencadeado observando "as forças causais que são críticas em diferentes pontos do processo" (TOLBERT; ZUCKER, 1999, p. 206). Encontrando assim, a UFPA, um caminho a seguir para chegar ao Estágio de total institucionalização (sedimentação), saindo do Estágio semi-institucional (objetivação), dentro de uma perspectiva que foi idealizada no Plano Estratégico Institucional de médio e longo prazo, contidas também no Plano de Gestão da UFPA no referido período estudado (2001 a 2009).

A mudança organizacional é o meio pelo qual a organização usa para se moldar ao ambiente. As incertezas ambientais, apresentadas neste estudo, mostram que a UFPA procurou obter legitimidade institucional pela definição de práticas homogêneas demandadas pelo seu ambiente organizacional, com o objetivo de institucionalizar tais práticas e torná-las habituais e aceitas. No processo, o maior desafio foi originar um modelo gerencial em que novos gestores (especialmente os técnicos da Universidade) assumissem o desafio de integrar ações estratégicas, táticas e operacionais, já que antes o planejamento era quase que exclusividade de docentes. No novo processo, técnicos passam a fazer parte da equipe estratégica do planejamento. 


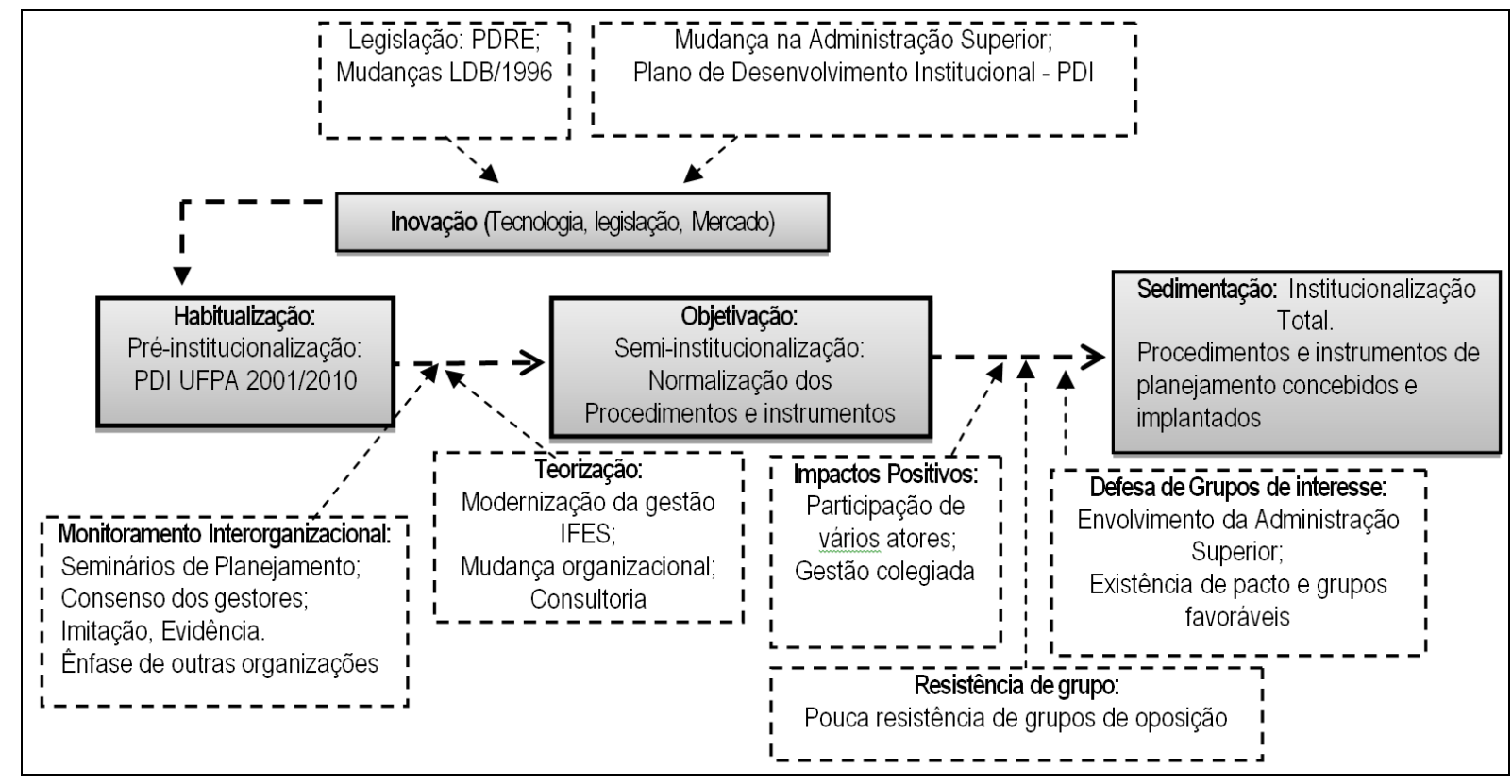

Figura 1 Processos inerentes à Institucionalização na UFPA Fonte: Adaptado de Tolbert e Zucker (1998, p. 207).

A UFPA passou a utilizar um modelo de gestão, na forma de planejar - o planejamento estratégico - com certo grau de incerteza, incentivando esta imitação comum em organizações que utilizam o mimetismo, na forma como proposto por Dimaggio e Powell (20005), de procedimentos bem sucedidos de outras organizações. A assimilação de normas e procedimentos foi consensual, com pouca resistência de grupos de oposição e apoio dos grupos defensores, sendo os resultados considerados positivos pela autoavaliação (2006 2008).

Também foi constatado que a partir de 2006 ocorreram mudanças estruturais nas unidades acadêmicas da UFPA, como resultado de procedimentos estabelecidos, tanto por força de Leis, como por decisões colegiadas decorrente de pactos, tornando estas unidades mais similares, pela aprovação e implementação dos novos regimentos e estatutos, bem como pela constituição de novas estruturas formais.

Observou-se que as estruturas que se tornaram razoavelmente difundidas podem ser descritas como estando no estágio de semi-institucionalização. Neste estágio, os adotantes (os que seguiram e acataram as novas concepções) são bastante heterogêneos. Logo, o ímpeto pela difusão deixa de ser somente uma imitação para adquirir uma estrutura mais normativa, refletindo a teorização implícita ou explícita das estruturas. Na medida em que a teorização se desenvolve e se torna mais explícita, diminui a variação na forma que as estruturas tomam em 
diferentes organizações, ou seja, as estruturas neste novo contexto tomam a forma dos adotantes.

\section{CONCLUSÃO}

A mudança organizacional verificada na experiência da implantação de um modelo de planejamento estratégico para a Universidade objeto do estudo revelou que tal modificação se deu na estrutura, já que foram criadas novas unidades. Quanto as mudanças no comportamento dos agentes, ocorreu quando novas experiências gerenciais foram verificadas nas unidades existentes e nas novas unidades, quando a adesão ao processo se deu de forma integral, o que se reflete no uso de novas tecnologias de gestão.

As mudanças na legislação federal, com a nova política de educação superior no Brasil, promoveram o uso de novas formas de avaliação institucional orientada pela busca de melhoria da qualidade e o planejamento institucional se materializa com resultado dessa orientação normativa. Já o processo de institucionalização estudado trouxe evidências de novas posturas da Universidade, como redefinição de sua missão, visão, objetivos e metas, além das estratégias e meios para isso.

A legislação induziu o processo de institucionalização e promoveu mudanças na forma de administrar a Universidade, que construiu uma gestão fundamentada na orientação gerencial. Fato este que mostra o aspecto característico das organizações públicas nacionais que é seu caráter legal-racional (não racional-legal), o que significa que a legislação conduz a administração. Os instrumentos e ações padronizados em um sistema de planejamento integrado contribuíram para aperfeiçoamento da gestão da Universidade, mesmo que o limitador deste processo ainda seja a ausência de acompanhamento do processo de planejamento estudado.

Desta forma os principais fatores que contribuíram com o processo de institucionalização do planejamento da universidade foram: a) mudanças na legislação, b) necessidade de maximização de recursos (financeiro, humanos, materiais e tecnológicos); c) mudança na gestão superior; d) troca de experiência com outras organizações universitárias; e) participação de consultores; f) percepção de melhorias por parte de gestores da Universidade; g) grupos favoráveis à mudança eram superiores aos que se oponham (baixa resistência).

A legitimação do processo institucionalizou o planejamento estratégico na Universidade também e teve como fundamento a busca por eficiência técnica e não apenas a 
legitimação da comunidade acadêmica, resultados semelhantes aos descritos pela literatura nacional recente, o que revela a pertinência de suas conclusões no campo da gestão universitária e, ao mesmo tempo, possibilita que novos estudos sejam realizados com perspectivas teóricas que sustentem outras pesquisas, porém a partir da percepção de seus usuários externos (alunos) e internos (servidores) sobre o planejamento na gestão universitária e seus reflexos no ensino superior.

\section{REFERÊNCIAS}

ABREU, Francisco de Assis M. de; ATHANÁZIO, Madeleine Mônica; PINHEIRO, Luiz Armando S. 2004. Universidade Federal do Pará: Plano de Desenvolvimento 2001/2010 Formulação e Avaliação de Resultados. In: CONFERÊNCIA SOBRE GESTÃO NAS IFES, 1, 2004, São Paulo. Anais... São Paulo: FORPLAD, 2004. p. 52.

ANSOFF, H. Igor; MCDONNELL, Edward J. Implantando a administração estratégica. São Paulo: Atlas, 1992.

ARAÚJO, Luis César Gonçalves de. Mudança Organizacional na Administração Pública Federal Brasileira. 1982. 307f. Tese (Doutorado em Administração). Escola de Administração de Empresas de São Paulo, Fundação Getúlio Vargas, São Paulo, 1982.

ASTLEY, W. Graham; VAN DE VEN, Andrew H. Debates e Perspectivas Centrais na Teoria das Organizações. Revista de Administração de Empresas, São Paulo, v. 45, n. 2, p.52-73, abr./jun. 2005.

BARBIER, René. A pesquisa-ação. Brasília: Liber, 2007. (Série Pesquisa).

BARDIN, Laurence. Análise de conteúdo. Lisboa: Edições 70, 2010.

BRASIL, Ministério da Administração e Reforma do Estado - MARE. Plano Diretor da Reforma do Aparelho do Estado. Brasília, 1995.

BRASIL. Presidência da República. Decreto n. 5.773 de 9 de maio de 2006. MINISTÉRIO DA EDUCAÇÃO - MEC. Diário Oficial da República Federativa do Brasil, Brasília, DF, Seção I. p. 6., 10 mai. 2006.

BRASIL. Presidência da República. Lei n. 10.172, de 9 de jan. de 2001. Plano Nacional de Educação e dá outras providências. Diário Oficial da República Federativa do Brasil, Brasília, Seção I. p. 1.10 jan. 2001.

BRASIL. Presidência da República. Lei n. 10.861, de 19 de abr. de 2004. Institui o Sistema Nacional de Avaliação da Educação Superior - SINAES. Diário Oficial da República Federativa do Brasil, Brasília, Seção I. p. 2. 15 abr. 2004.

BRASIL. Presidência da República. Lei n. 9.394, de 20 de dez. de 1996. Lei de diretrizes e bases da educação nacional - LDB. Diário Oficial da República Federativa do Brasil, Brasília, Seção I. p. 27833.23 dez. 1996. 
CLEGG, S. R.; HARDY, C. Introdução: organização e estudos organizacionais. In: CLEGG, S.; HARDY, C.; NORD, W. R. (Org.); CALDAS, Miguel. P.; FACHIN, Roberto; FISCHER, Tânia (Org. edição brasileira). Handbook de Estudos Organizacionais, v. 1. São Paulo: Atlas, 1999.

DIMAGGIO, Paul Joseph; POWELL, Jaula de ferro revisitada: isomorfismo institucional e racionalidade coletiva nos campos organizacionais. In: CALDAS, Miguel P.; BERTERO, Carlos Osmar (Coord.). Teoria das Organizações (Série RAE-Clássicos). São Paulo: Atlas, 2005.

ETZIONI, Emitai. Organizações complexas: estudo das organizações em face dos problemas sociais. São Paulo: Atlas, 1976.

FARIAS FILHO; M. C.; ARRUDA FILHO, E. J. Planejamento da pesquisa científica. São Paulo: Atlas, 2013.

FRANCISCO, T. H. A.; RAMOS, A. M.; OTANI, N.; HELOU, A. R. H. A.; MICHELS, E. O impacto da estrutura legal do PDI no processo de planejamento estratégico de instituições do sistema AMPESC. Revista Gual, Edição Especial, p.133-162, 2011.

KAHVECI, T. C.; UYGUN, O.; TEKEZ, E. K.; SEVINÇLI, A.; KILIÇARSLAN, G.; DULGER, E. Evaluation of public strategic planning models for Turkish Universities.

Procedia - Social and Behavioral Sciences, v.58, p.138-148, 2012.

MEYER JÚNIOR, Victor; SERMANN, Lucia Izabel Czerwonka; MANGOLIM, Lúcia. Planejamento e Gestão Estratégica: Viabilidade nas IES. COLÓQUIO INTERNACIONAL SOBRE GESTÃO UNIVERSITÁRIA NA AMÉRICA DO SUL, 4. Florianópolis, SC. 2004. Disponível em: < http://www.inpeau.ufsc.br/ivcoloquio/a0index.php $>$. Acesso em: 21 set. 2010.

MEYER, John W.; ROWAN, Brian. Organizaciones institucionalizadas: la estructura formal como mito y cerimonia. In: DIMAGGIO, Paul J.; POWELL, Walter W. (Comp.). EI nuevo institucionalismo en el análisis organizacional. México: Fondo de Cultura Económica, 2001.

MINTZBERG, H. (1978). Patterns in Strategy Formation. Management Science, 24, 934948.

MIZAEL, G. A.; PEREIRA; J. R.; VILAS BOAS, A. A.; FERREIRA, M. F. de A. Avaliação do plano de desenvolvimento institucional das universidades federais do consórcio SulSudeste de Minas Gerais. Revisa Gual, Edição Especial, p.21-42, 2012.

ORRU, Marco; BIGGART; Nicole W.; HAMILTON, Bracy G. Isomorfiomo organizacional en Asia Oriental. In: DIMAGGIO, Paul J.; POWELL, Walter W. (Comp.). EI nuevo institucionalismo en el análisis organizacional. México: Fondo de Cultura Económica, 2001.

PICCHIAI, Djair. O plano de desenvolvimento institucional e o projeto pedagógico institucional de universidades públicas: limites organizacionais. Revista Gual, v.5, n.3, p.2345, dez., 2012.

RIZZATTI, Gerson; RIZZATTI JUNIOR, Gerson. Organização Universitária: mudanças na administração e nas funções administrativas. COLÓQUIO INTERNACIONAL SOBRE 
GESTÃO UNIVERSITÁRIA NA AMÉRICA DO SUL, 4. Florianópolis, SC. 2004.

Disponível em: < http://www.inpeau.ufsc.br/ivcoloquio/a0index.php >. Acesso em: 21 set. 2010.

ROBBINS, S. P. Comportamento organizacional. 9. ed, São Paulo: Prentice Hall, 2002.

RODRIGUES, Cláudia M. C. Aplicação do modelo de avaliação integrado ao planejamento anual na Faculdade da serra Gaúcha (FSG): um estudo de caso. Revista Gual, v.4, n.2, p.2952, mai./ago., 2011.

SCOTT, W. Richard. Retomando los argumentos institucionales. In: DIMAGGIO, Paul J.; POWELL, Walter W. (Comp.). EI nuevo institucionalismo en el análisis organizacional. México: Fondo de Cultura Económica, 2001.

SILVA, P. M.; CARVALHO, W. W. de; CARVALHO, F. A.; FURTADO, R. P. M. Planejamento orçamentário: as práticas da Universidade Federal de Lavras. Revista Gual, v.5, n.4, p.209-227, Edição Especial, 2012.

TOLBERT, Pamela S.; ZUCKER, Lynne. G. A institucionalização da teoria institucional. In: CLEGG, S.; HARDY, C.; NORD, W. R. (Org.); CALDAS, Miguel. P.; FACHIN, Roberto; FISCHER, Tânia (Org. edição brasileira). Handbook de Estudos Organizacionais, v. 1. São Paulo: Atlas, 1999.

UFPA. Universidade Federal do Pará. Pró-Reitoria de Planejamento e Desenvolvimento Institucional. Departamento de Informações Institucionais. Anuário Estatístico 2012 - Ano Base 2011/UFPA. Belém: EDUFPA. jul. 2012. 253p. 2012.

UFPA. Universidade Federal do Pará. Pró-Reitoria de Planejamento e Desenvolvimento. Departamento de Avaliação Institucional. Comissão Própria de Avaliação. Avalia: Programa de Auto-avaliação da UFPA. Auto-Avaliação: relatório técnico. Belém: EDUFPA, ago. 2006.

UFPA. Universidade Federal do Pará. Pró-Reitoria de Planejamento e Desenvolvimento Institucional. Departamento de Planejamento. Plano de Desenvolvimento da Universidade Federal do Pará: 2001-2010. Universidade Federal do Pará. Belém: EDUFPA, 2003. 180 p.

UFPA. Universidade Federal do Pará. Pró-Reitoria de Planejamento e Desenvolvimento Institucional. Departamento de Planejamento. Relatório de Gestão 2001-2006. Belém, 2007. $246 \mathrm{p}$.

UFPA. Universidade Federal do Pará. Pró-Reitoria de Planejamento e Desenvolvimento Institucional. Departamento de Planejamento. Seminários de Orientação para elaboração de Planos de Gestão das Unidades Acadêmicas da UFPA: relatório técnico. Belém, 2008. $519 \mathrm{p}$.

WOOD JR, Thomaz. Mudança organizacional: introdução ao tema. In: WOOD JR, Thomaz (org.). Mudança organizacional: aprofundando temas atuais em administração de empresas. São Paulo: Atlas, 2000.

WOOD JR, Thomaz; CURADO, I.; CAMPOS, H. Vencendo a crise: mudança organizacional na Rhodia Farma. In: WOOD Jr., T., Mudança organizacional. São Paulo: Atlas, 2000. 